\title{
O EFEITO DO ULTRA-SOM EM REAÇÕES QUÍMICAS
}

Marco Antonio Utrera Martines, Marian Rosaly Davolos e Miguel Jafelicci Júnior

Instituto de Química - Universidade Estadual Paulista - UNESP - CP 355 - 14801-970 - Araraquara - SP

Recebido em 2/2/99; aceito em 16/6/99

\begin{abstract}
THE ULTRASOUND EFFECT ON CHEMISTRY REACTIONS. Unusual chemical phenomenon associated with ultrasound is on account of cavitation effect. The ultrasound increase the rate and yield of chemical reaction on account of its ability to emulsify liquids. When the ultrasound is used in metallic catalyst reaction the activity of catalyst is increased because the ultrasound clean the surface of catalyst. Sonogels have a fine porosity and large specific surface improving different properties. This paper deals with ultrasound phenomenon and gives some examples of reactions and properties where this radiation takes an important role.
\end{abstract}

Keywords: ultrasound; sonochemistry; sonoluminescence; and sonogel.

\section{HISTÓRICO}

A descoberta do ultra-som ocorreu em 1880 por Curie estudando o efeito piezelétrico ${ }^{1}$. Thornycroft e Barnaby em 1894 observaram que na propulsão de mísseis lançados pelo destróier uma fonte de vibração era gerada causando implosão de bolhas e/ou cavidades na água ${ }^{2,3}$. Essa vibração ficou conhecida como cavitação.

Com o naufrágio do Titanic, causado por um Iceberg, houve uma preocupação muito grande em se conhecer a topografia do fundo do mar. Langevin em 1912 desenvolveu um aparelho capaz de medir a profundidade do mar, atualmente conhecido como SONAR (Sound Navigation And Ranging). O SONAR envia um pulso de ultra-som da quilha de um barco para o fundo do mar e esta onda é refletida para um detector, o qual também está situado na quilha. O intervalo de tempo entre o envio e o recebimento do pulso permite a determinação da profundidade, já que a profundidade é igual ao produto da metade do intervalo de tempo pela velocidade do som na água ${ }^{1}$.

Lord Rayleigh, em 1917, demonstrou que no lançamento de mísseis de um destróier, a vibração ocorre devido à turbulência, ao calor e à pressão das cavidades implodindo. Mesmo com o desenvolvimento de mísseis mais modernos não se conseguiu solucionar o problema de cavitação ${ }^{2}$.

Em 1927, Alfredo Loomis foi o primeiro químico a reconhecer o efeito anômalo de ondas sonoras intensas propagando-se pelo líquido. Este efeito é denominado de efeito sonoquímico. A partir de 1980 a sonoquímica sofreu grande avanço e muitos trabalhos foram publicados em diferentes sistemas ${ }^{2}$.

O ultra-som é usado na indústria ${ }^{1,2}$ para limpeza de materiais, solda de plásticos, processos químicos, preparação de emulsão e suspensão, desgaseificação de solventes e avaliação não-destrutiva ${ }^{4}$ em materiais, isto é, a obtenção de informações sobre defeitos, fraturas, aglomerados, inclusão e anisotropia; em hospitais para análise de imagem $^{2}$ e estimulação do calo ósseo ${ }^{5,6}$.

\section{FUNDAMENTOS}

Transformações químicas e físicas podem ocorrer devido à interação da radiação com a matéria. Então, é importante entender o fenômeno e conhecer o efeito da radiação ultra-sônica nestas transformações.

Pela Figura 1 pode-se ter uma idéia da freqüência do ultrasom em relação à sensibilidade do ouvido humano. A sensibilidade do ouvido humano está na faixa de $16 \mathrm{~Hz}$ a $16 \mathrm{KHz}$, a frequiência característica de ultra-som, em geral, está no intervalo de $16 \mathrm{KHz}$ a $1 \mathrm{MHz}$. Sendo que freqüências de 1 a $10 \mathrm{MHz}$ correspondem à região de alta frequência ${ }^{1,7}$. O símbolo internacional de ultra-som é ))).

\section{FREQUÊNCIA DE SOM $(\mathrm{Hz})$}

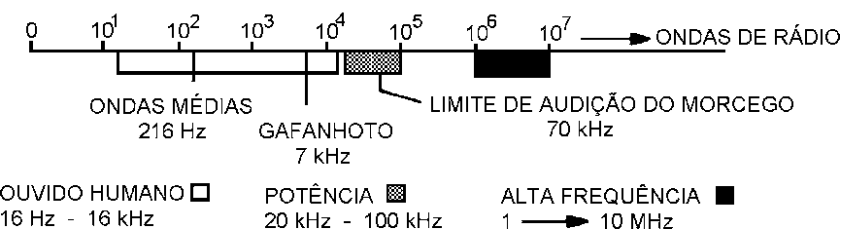

Figura 1. Região de freqüência do som $^{7}$.

A propagação de ultra-som pode ser ilustrada através do movimento de um diapasão no meio de propagação, Figura 2. Quando o diapasão entra em movimento expandindo-se (Figura 2a) há compressão do sistema, comprimindo as moléculas mais próximas, representada no primeiro nodo da onda. Quando entra em equilíbrio não há compressão e nem expansão próximo do diapasão (Figura 2b). Quando se comprime ocorre descompressão do sistema de moléculas do meio de propagação (Figura 2c). Portanto, o movimento do diapasão causa um movimento periódico de compressão e expansão das moléculas adjacentes (Figura 2d), resultando na propagação das ondas ultra-sônicas ${ }^{8}$.

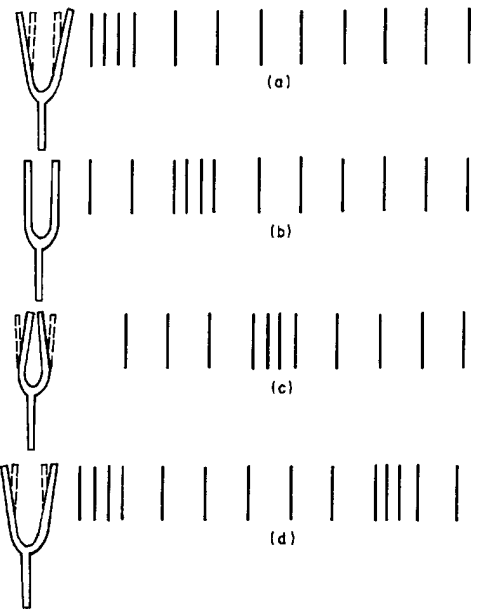

Figura 2. Ondas de pressão no ar produzidas por diapasão ${ }^{8}$. 
Para que haja propagação das ondas ultra-sônicas é necessário que o meio de propagação tenha propriedades elásticas. Então, o movimento de um corpo vibrando é transmitido às moléculas adjacentes, as quais, antes de retornarem à posição de equilíbrio, transmitem esse movimento para as moléculas que estão ao redor. Esse movimento periódico cria ciclos de compressão e expansão ${ }^{8}$, característico do fenômeno de cavitação.

As ondas ultra-sônicas geram pressão acústica ${ }^{1,8}(\mathrm{PA})$ no meio de propagação que é dada pela equação 1 :

$\mathrm{P}_{\mathrm{a}}=\mathrm{P}_{\mathrm{A}} \operatorname{sen} 2 \pi \mathrm{ft}$

com: $\mathrm{P}_{\mathrm{a}}=$ pressão adicional à pressão hidrostática $\left(\mathrm{P}_{\mathrm{h}}\right)$ ambiente;

$\mathrm{P}_{\mathrm{A}}=$ pressão de amplitude máxima da onda;

$\mathrm{f}=$ freqüência da onda $(>16 \mathrm{KHz})$;

$\mathrm{t}=$ tempo.

A intensidade ${ }^{1,8}$ (I) é dada pela equação 2:

$\mathrm{I}=\mathrm{P}_{\mathrm{A}}^{2} / 2 \rho \mathrm{c}$

com: $\rho=$ densidade do meio;

$\mathrm{c}=$ velocidade do som no meio.

A propagação das ondas ultra-sônicas é atenuada devido à vibração das moléculas do meio de propagação, como conseqüência ocorre o abaixamento da energia dessas ondas. A atenuação ${ }^{1,8}$ é dada pela equação 3 :

$\mathrm{I}=\mathrm{I}_{0} \exp (-2 \alpha l)$

com: $\quad \mathrm{I}=$ intensidade atenuada;

$\mathrm{I}_{0}=$ intensidade da fonte de radiação;

$\alpha=$ coeficiente de absorção;

l = distância da fonte de radiação.

Kirchoff $^{9}$ deduziu uma expressão que relaciona o coeficiente de absorção $(\alpha)$ com a viscosidade e com a condutividade do meio, equação 4:

$\alpha=\frac{2 \pi^{2} \mathrm{f}^{2}}{\rho \mathrm{c}^{3}}\left[\eta_{\mathrm{b}}+\frac{4}{3} \eta_{\mathrm{s}}+\frac{(\gamma-1) \kappa^{\prime}}{\mathrm{C}_{\mathrm{p}}}\right]$

onde: $\eta_{\mathrm{S}}=$ força de cisalhamento;

$\eta_{\mathrm{b}}=$ viscosidade da cavidade;

$\mathrm{k}^{6}$ = condutividade térmica do meio;

$\mathrm{C}_{\mathrm{p}}=$ calor específico à pressão constante;

$\gamma=$ capacidade calorífica.

Por exemplo, admitindo-se onda ultra-sônica ${ }^{1}$ com frequiência de $20 \mathrm{KHz}$, a intensidade ao percorrer uma distância de 30 $\mathrm{Km}$ reduzir-se-á à metade. Ao passo que para uma onda ultrasônica com freqüência de $118 \mathrm{KHz}$, a intensidade se reduzirá à metade ao percorrer uma distância de $1 \mathrm{Km}$.

A produção de ultra-som é um fenômeno físico ${ }^{2}$ baseado no processo de criar, aumentar e implodir cavidades de vapor e gases, denominado cavitação, em um líquido promovendo efeitos de ativação em reações químicas. Durante a etapa de compressão a pressão é positiva, enquanto que a expansão resulta em "vácuo", chamado de pressão negativa, constituindo-se em um ciclo de compressão-expansão que gera as cavidades ${ }^{2}$.

Num líquido com partículas sólidas dispersas, os gases são adsorvidos nos poros das partículas ${ }^{1,8,10}$ como ilustrado nas Figuras 3 e 4 . Na etapa de compressão os gases ou vapores, no interior da cavidade, são comprimidos para o interior da partícula, Figura 3a; e na etapa de expansão esses gases ou vapores são dirigidos para fora da partícula, Figura $3 \mathrm{~b}$. A cavidade aumenta de tamanho em direção ao interior do líquido, separa-se da partícula permanecendo um núcleo na cavidade ${ }^{10}$, Figura 4.

A origem da cavitação se deve ao fato que, durante a expansão, os gases adsorvidos no líquido ao redor da cavidade ou na interface, evaporam-se resultando na expansão da cavidade.

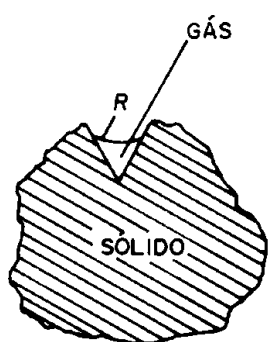

(a)

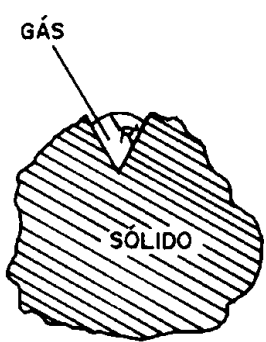

(b)
Figura 3. Efeito da pressão nos gás aprisionado na fenda (poro) de uma partícula: (a) pressão positiva; (b) pressão negatival.

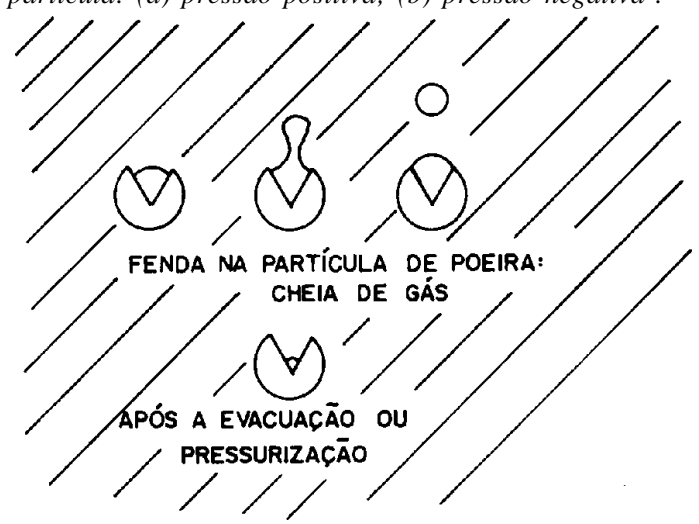

Figura 4. Nucleação da cavidade acústica ${ }^{10}$.

Durante a etapa de compressão estes gases ou vapores não retornam completamente ao líquido, resultando num aumento efetivo da cavidade. Ciclos periódicos de compressão e expansão causam aumento do tamanho da cavidade. A cavidade ao atingir um tamanho crítico implode-se, liberando grande quantidade de calor e pressão num curto período de tempo e em pontos localizados do líquido ${ }^{1,2}$. Estas etapas estão representadas na Figura 5.

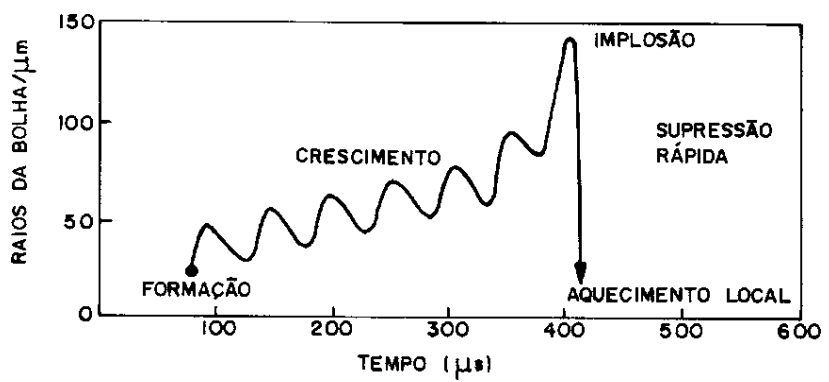

Figura 5. Crescimento de bolha e implosão num líquido irradiado com ultra-som ${ }^{2}$.

A temperatura e a pressão exatas, durante a implosão, não é fácil de ser calculada teoricamente ou medida experimentalmente ${ }^{1,2,3,8}$. No ultra-som a precisão do termômetro é comprometida devido ao tempo de alcance do equilíbrio térmico entre o termômetro e o meio líquido de propagação. Portanto, o termômetro mede a média do aquecimento da compressão e de resfriamento da expansão. A temperatura da implosão ${ }^{2}$ foi determinada indiretamente baseando-se na dependência da cinética de reações conhecidas em função de temperatura. Concluindo que a temperatura de implosão no interior da cavidade é cerca de $5500^{\circ} \mathrm{C}$, enquanto que ao redor da cavidade é cerca de $2100^{\circ} \mathrm{C}$. A pressão é estimada em torno de $500 \mathrm{~atm}$. Pode-se comparar a temperatura média com a chama do acetileno que é aproximadamente $2400^{\circ} \mathrm{C}$. Os valores de temperatura e pressão foram obtidos teoricamente ${ }^{1}$, admitindo-se que na etapa final da implosão a cavidade continha nitrogênio (calor 
específico, $\gamma=1,33)$ em água à temperatura ambiente $\left(20^{\circ} \mathrm{C}\right) \mathrm{e}$ pressão ambiente $10^{5} \mathrm{~Pa}(0,987$ atm.). Os valores calculados foram $3925^{\circ} \mathrm{C}$ e $9,75.10^{7} \mathrm{~Pa}$ (962 atm.), respectivamente.

Esses valores de temperatura e pressão alcançados em pontos locais por período de tempo muito curto, durante a implosão da cavidade, provocam um efeito não usual em reações químicas.

\section{SÍNTESE ORGÂNICA}

Em reações químicas alguns exemplos nos quais o ultrasom desempenha papel importante estão citados a seguir. Em reações de alquilação do indol ${ }^{11}$, equação 5 , o ultra-som favorece a interação entre diferentes fases e a migração do nucleófilo para a fase orgânica, tornando o ataque mais fácil. A utilização de ultra-som aumentou o rendimento de $19 \%$ para $90 \%$, diminuindo o tempo de reação de 3 horas para 1,3 horas e aumentando a pureza do produto obtido.

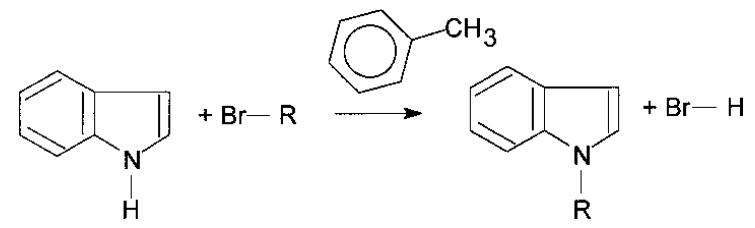

com: $\mathrm{R}=\mathrm{CH}_{2}-\left(\mathrm{CH}_{2}\right)_{10}-\mathrm{CH}_{3}$

$\mathrm{Na}$ hidrólise de éster ${ }^{11}$, equação 6 , o ultra-som aumentou o rendimento e a velocidade de reação, Tabela 1 , porque favoreceu a formação de emulsão mais estável de partículas pequenas dos reagentes.<smiles>COC(=O)c1ccccc1C</smiles>

Tabela 1. Comparação de rendimento e de velocidade de reação de hidrólise de éster para os métodos de obtenção sob refluxo e sob ultra-som ${ }^{11}$.

\begin{tabular}{ccc}
\hline tempo de reação/min. & condição & rendimento/\% \\
\hline 90 & refluxo & 15 \\
10 & ultra-som & 15 \\
60 & ultra-som & 94 \\
\hline
\end{tabular}

A redução de hidrocarbonetos aromáticos com metal alcalino ${ }^{11}$ para formar radicais aniônicos, equação 7 , é favorecida pelo uso de ultra-som. O ultra-som fragmenta e limpa a superfície do metal, removendo a camada de hidróxido formada em sua superfície, aumentando a área de contado do reagente com a do catalisador.

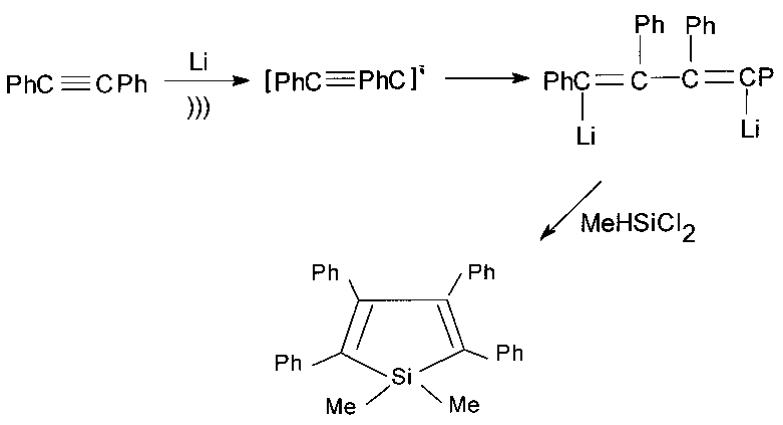

Reação contendo zinco metálico como catalisador ${ }^{11}$ é favorecida pela utilização de ultra-som que limpa a superfície do zinco, facilitando o transporte dos reagentes na superfície, e provavelmente, a erosão do zinco pode gerar partículas de zinco pequenas. Por exemplo, na reação de produção de quinona dimetídeo, equação 8 .

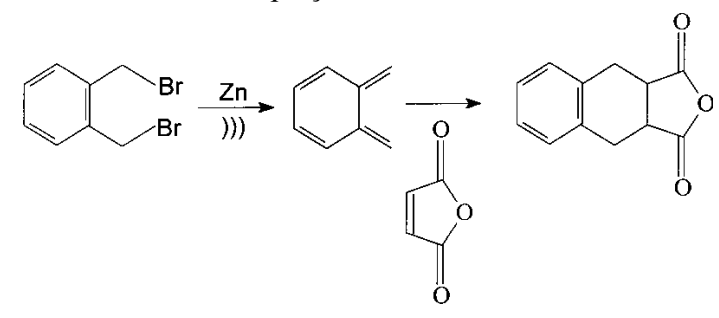

Na reação de Simmons-Smith do diiodometano o ultra-som é muito útil na geração de carbeno, equação 9. A reação de ciclopropagação ocorre usando-se zinco como catalisador, e portanto, dispensando o catalisador zinco-cobre ${ }^{12}$.

$\mathrm{CH}_{2} \mathrm{I}_{2}+=+\mathrm{Zn} \underset{\text { )) })}{\longrightarrow}(60-75 \%)$

Barboza et al. ${ }^{13}$ concluíram que a utilização do ultra-som em reações químicas possui algumas vantagens, entre elas: redução do tempo de reação; redução da quantidade de reagentes; aumento de rendimento; seletividade; favorecimento de reações que normalmente não ocorrem em condições normais.

Uma área muito próspera de pesquisa é a preparação de compostos instáveis. Boudjouk ${ }^{12}$ utilizou métodos de sonificação em fluxo para isolar espécies reativas e produtos intermediários que são muito utilizados em sínteses orgânicas.

Redução de haletos metálicos binários ${ }^{12}$ resulta em pós metálicos finamente divididos que são considerados mais reativos que pós disponíveis comercialmente. $\mathrm{O}$ ultra-som não apenas acelera a redução, mas também aumenta a reatividade do pó metálico produzido, equação 10 .

$\mathrm{M}_{1} \mathrm{X}_{\mathrm{n}}+\mathrm{nM}_{2} \stackrel{()))}{\longrightarrow} \mathrm{M}_{1}+\mathrm{nM}_{2} X$

com: $\mathrm{M}_{1}=\mathrm{Mg}, \mathrm{Ca}, \mathrm{B}, \mathrm{Al}, \mathrm{Si}, \mathrm{Ge}, \mathrm{Sn}, \mathrm{Pb}, \mathrm{Ti}, \mathrm{V}, \mathrm{Cr}, \mathrm{Mn}, \mathrm{Fe}$, $\mathrm{Co}, \mathrm{Ni}, \mathrm{Cu}, \mathrm{Zn}, \mathrm{Nb}, \mathrm{Mo}, \mathrm{Pb}$, Ta e Pt;

$\mathrm{M}_{2}=\mathrm{Li}, \mathrm{Na}$ e $\mathrm{K}$.

\section{DEGRADAÇÃO DE POLÍMERO}

A exposição prolongada de soluções contendo macromoléculas $^{1}$ em ultra-som de alta energia $\left(>10 \mathrm{~W} . \mathrm{cm}^{-2}\right)$ produz redução permanente na viscosidade da solução. A degradação das cadeias do polímero ocorre mesmo com o sistema estando desgaseificado ou pressurizado. A degradação é devida ao aumento das forças de fricção desenvolvidas entre o rápido movimento das moléculas grandes e com menor mobilidade. Evidências experimentais sugerem que a degradação é causada por: (i) forças hidrodinâmicas da cavitação (isto é a energia de onda de choque produzida na implosão da bolha), (ii) tensão de cisalhamento na interface das bolhas pulsando, ou (iii) efeito térmico associado com efeito químico tanto da cavitação estável como da transitória. Todos são dependentes dos mesmos fatores, isto é, intensidade, freqüência do ultra-som, quantidade e tipo de gás. Gases diatômicos $\left(\mathrm{N}_{2}, \mathrm{O}_{2}, \mathrm{H}_{2}\right)$ aumentam a despolimerização enquanto gases poliatômicos diferentes $\left(\mathrm{NH}_{3}, \mathrm{SO}_{2}, \mathrm{CO}_{2}\right)$ inibem a despolimerização porque têm solubilidade e capacidade calorífica $(\gamma)^{1}$ diferentes. O uso de solvente menos volátil ou temperatura menor ${ }^{14}$ resulta em pressão de vapor $\left(\mathrm{P}_{\mathrm{v}}\right)$ menor e causa aumento na despolimerização. $\mathrm{O}$ aumento da intensidade ${ }^{14}$ ultra-sônica aumenta o grau de despolimerização.

A velocidade de oxidação de iodeto e degradação de cadeia principal de poliacrilamida, em solução aquosa, aumenta rapidamente com o aumento de intensidade ultra-sônica. Quando se usa ultra-som de $20 \mathrm{KHz}$, a ruptura de partículas grandes independe da formação ou presença de radicais livres ${ }^{15}$. 


\section{POLIMERIZAÇÃO}

A utilização de ultra-som para iniciar a copolimerização ${ }^{14} \mathrm{de}$ sistemas contendo apenas monômero ou monômero mais iniciador tem recebido pouca atenção, devido ao fato que à medida que a polimerização ocorre e a concentração do polímero aumenta, a reação de competição de despolimerização torna-se cada vez mais significante. $\mathrm{O}$ efeito de ultra-som pulsado numa determinada freqüência no grau de polimerização de acrilamida em água ${ }^{1}$ depende da duração do pulso. Quando a duração do pulso é reduzida o grau da polimerização também diminui.

Donaldson et al. ${ }^{16}$ estudaram os efeitos de gases adsorvidos no solvente e de solventes com pressão de vapor alta na razão de polimerização de nitrobenzeno. Quanto ao efeito de gases adsorvidos, eles observaram que o hidrogênio inibe a polimerização do nitrobenzeno com maior eficiência. A inibição diminui na ordem: nitrogênio, hélio, oxigênio e argônio. $\mathrm{O}$ uso de solvente com pressão de vapor alta, por exemplo acetona e álcool, também inibe a polimerização térmica mínima durante o colapso da bolha.

A cinética de polimerização de acrilonitrila ${ }^{17}$ em solução aquosa diluída envolve inicialmente a formação de radicais livres que são requeridos em várias reações secundárias. Uma fração destes radicais livres primários e secundários está disponível para induzir a polimerização dos monômeros presentes. No entanto, a produção destes radicais livres também é responsável pela reação de despolimerização causada por ondas ultra-sônicas.

\section{SONOLUMINESCÊNCIA}

Sonoluminescência ${ }^{2,3}$ é o nome dado a emissão de luz excitada por cavitação acústica em meios aquosos e não aquosos. Em ambos os casos a emissão de luz ${ }^{2,3}$ é o resultado da formação de espécies químicas reativas no estado eletrônico excitado causada pela alta temperatura local. A emissão de luz pode ser utilizada como uma sonda espectroscópica de eventos de cavitação, ou seja servir como indicadora dos fenômenos ultrasônicos. Os mecanismos da sonoluminescência em sistemas aquosos foram muito discutidos na literatura ${ }^{1}$ e explicados com base em teorias térmicas e elétricas envolvendo a recombinação de radicais ou íons. O primeiro espectro de sonoluminescência de hidrocarboneto foi apresentado por Suslick e Flint ${ }^{18}$.

$\mathrm{O}$ espectro de sonoluminescência do dodecano obtido a $-4^{\circ} \mathrm{C}$, Figura 6, origina do estado excitado $\mathrm{C}_{2}$, especificamente da transição do estado $d^{3} \Pi_{g}$ para o estado a ${ }^{3} \Pi_{\mathrm{u}}$ e é chamada de banda de Swan. As quatro bandas a 435, 465, 510 e $550 \mathrm{~nm}$ correspondem a $\Delta \mathrm{n}=+2,+1,0, \mathrm{e}-1$ dos múltiplos vibracionais, respectivamente. Sonólise de hidrocarbonetos ${ }^{18}$ à temperatura inferior a $0^{\circ} \mathrm{C}$, leva à formação de hidrogênio $\left(\mathrm{H}_{2}\right)$, metano $\left(\mathrm{CH}_{4}\right)$ e acetileno $\left(\mathrm{C}_{2} \mathrm{H}_{2}\right)$, consistente com a sonoluminescência observada. À temperatura efetiva estimada durante a cavitação no solvente alcano é de $\sim 4900^{\circ} \mathrm{C}$ na fase gás e de $\sim 1600^{\circ} \mathrm{C}$ na região líquida. Este espectro de sonoluminescência é semelhante ao espectro de quimiluninescência do benzeno e acetileno produzido por pirólise e a emissão, banda Swan, é atribuída ao $\mathrm{C}_{2}\left(\mathrm{~d}^{3} \Pi_{\mathrm{g}}\right)$. Uma reação responsável de geração do $\mathrm{C}_{2}\left(\mathrm{~d}^{3} \Pi_{\mathrm{g}}\right)$, equação 11 , foi evidenciada por Grebe e Homann ${ }^{19}$ estudando reações em fase gasosa de acetileno com átomos de oxigênio e de hidrogênio $\left(\mathrm{C}_{2} \mathrm{H}_{2} / \mathrm{O} / \mathrm{H}\right)$ num reator de fluxo de descarga de baixa pressão.

$\mathrm{C}+\mathrm{CH}_{2} \rightarrow \mathrm{C}_{2}^{*}+\mathrm{H}_{2}$

\section{SONÓLISE}

O efeito químico do ultra-som em soluções aquosas é de muito interesse na medicina devido à sua grande utilização em diagnóstico e terapia. Na literatura ${ }^{20}$, foi relatado que o ultra-som intenso causa perigo químico através do fenômeno de cavitação. No estudo de sonólise de soluções aquosas foi

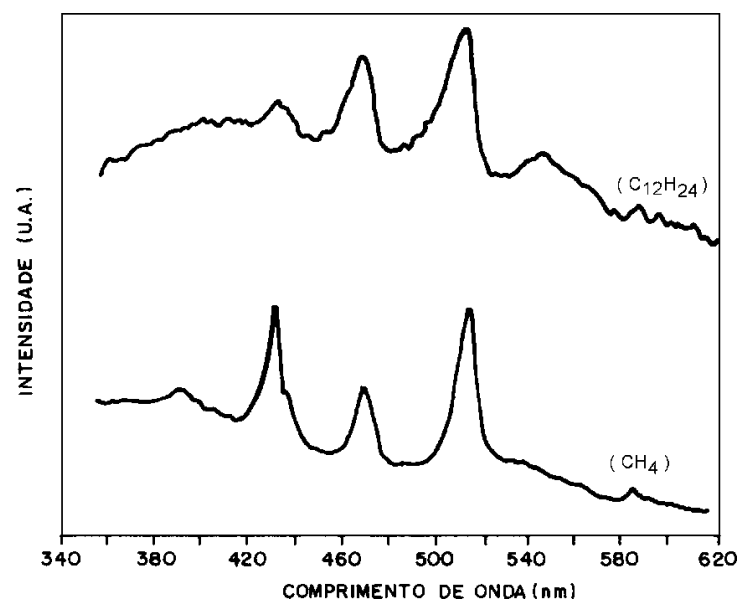

Figura 6. Espectro de emissão: (a) espectro de sonoluminescência do dodecano $\left(\mathrm{C}_{12} \mathrm{H}_{24}\right)$ a $-4^{\circ} \mathrm{C}$; (b) combustão do metano $\left(\mathrm{CH}_{4}\right)^{2}$.

proposto que radicais hidroxílicos $(\cdot \mathrm{OH})$ e átomos de hidrogênio $(\cdot \mathrm{H})$ são produzidos pelo ultra-som ${ }^{21}$.

A sonicação de solução aquosa de 4,4-dimetil-1-pirrolina-1óxido (DMPO), 4-[(1,1-dimetiletil)imino]metil-metilpiridinium $\mathrm{N}$-óxido (PYBN) e 2-metil-N-(4-piridinilmetileno)-2-propanamina $\mathrm{N}, \mathrm{N}$ '-dióxido (POBN) resulta na formação de radicais hidroxílicos e átomos de hidrogênio. Esses radicais foram detectados por ressonância de spin eletrônico (ESR) e pela identificação dos adutos: (H-DMPO), (OH-DMPO), (H-PYBN), $(\mathrm{OH}-\mathrm{PYBN}),(\mathrm{H}-\mathrm{POBN})$ e $(\mathrm{OH}-\mathrm{POBN})^{22,23}$.

Soluções aquosas de acrilamida, ou ácido fórmico, ou aliltiouréia, saturadas com oxigênio ou argônio, quando irradiadas com ondas ultra-sônicas resultam na formação de radical •OH que é um intermediário na produção sonoquímica de peróxido de hidrogênio ${ }^{21}$.

A reação de polimerização de acrilonitrila em meio aquoso induzida por ultra-som ${ }^{17}$ envolve inicialmente a formação de radicais hidrogênio e hidroxílico, equação 13. Explicando os efeitos de oxidação e redução em solução aquosa tratada com ondas ultra-sônicas Lindström e Lamm $^{17}$ sugeriram que o aumento da oxidação na presença de oxigênio dissolvido não depende muito da ativação direta do oxigênio na cavitação como acontece com o efeito exercido pelo oxigênio molecular nas reações secundárias na qual os radicais ${ }^{\circ} \mathrm{OH}$ e ${ }^{\bullet} \mathrm{H}$ fazem parte.

$$
\mathrm{H}_{2} \mathrm{O} \rightarrow{ }^{\bullet} \mathrm{H}+{ }^{\bullet} \mathrm{OH}
$$

\section{SONOGÉIS}

A estrutura de géis de sílica obtidos classicamente consistem de matrizes com baixa densidade, com poros grandes e superfície extremamente rugosa, mas com interface pontiaguda. Os sonogéis possuem baixa porosidade. Os poros são aproximadamente esféricos indicando uma superfície lisa e alta uniformidade na distribuição dos agregados ${ }^{24}$.

A utilização de ultra-som na precipitação de sílica contendo crômio ${ }^{25}$, a partir de silicato de sódio solúvel nas temperaturas de 50 ou $80^{\circ} \mathrm{C}$, promove formação de partículas finas com superfície elevada. No entanto, a $50^{\circ} \mathrm{C}$ a radiação ultrasônica além desse efeito provavelmente também promove a condensação de grupos $\mathrm{SiOH}$.

Precipitado de sulfeto seleneto de cádmio pode ser incorporado em sol-gel hospedeiro, usando técnica que requer a difusão de um mínimo de componente no gel. A única diferença provável entre as matrizes obtidas pelo método clássico e sob 
ultra-som foi sua porosidade que modifica as propriedades ópticas do material ${ }^{26}$.

Partículas esféricas de sílica preparadas sob energia ultrasônica, a partir de TEOS, $\mathrm{NH}_{3}$ e $\mathrm{H}_{2} \mathrm{O}$ (método Stöber) ${ }^{27}$, apresentam aumento do tamanho de partícula com o aumento da intensidade ultra-sônica. No entanto, o aumento da intensidade de sonificação, a $20 \mathrm{kHz}$, induz a aglomeração das esferas.

Monolitos e vidro completamente densos ${ }^{28}$ foram obtidos a partir de xerogel de sílica e formamida preparados sob energia ultra-sônica. A eficiência do processo de sinterização é atribuída à formação de ligação de hidrogênio da formamida com $\mathrm{OH}$ da superfície da sílica.

\section{PREPARAÇÃO DE CATALISADORES}

Na obtenção de compostos organometálicos é muito importante a utilização de ultra-som. A reação de carbonilação ${ }^{7}$ apresentada na equação 12 ilustra o efeito do ultra-som. A metodologia clássica requer condições de temperatura e pressão altas, $160^{\circ} \mathrm{C}$ e 200 atm., respectivamente. Utilizando ultrasom estas condições podem ser reduzidas para $10^{\circ} \mathrm{C}$ e $4,3.10^{5}$ $\mathrm{Pa}$ (4,4 atm.), respectivamente.

$$
\mathrm{VCl}_{3} \cdot(\mathrm{THF})_{3} \underset{\mathrm{THF}}{\stackrel{\mathrm{CO} / \mathrm{Na}}{\longrightarrow}} \mathrm{V}(\mathrm{CO})_{6}^{-}
$$

A utilização de ultra-som durante a preparação de catalisadores sólidos conduz a uma melhora da atividade catalítica quando comparado com catalisador preparado por métodos quimicamente similares empregando apenas agitação mecânica. Platina negra, preparada a partir de solução aquosa de sais de platina com formaldeído sob ultra-som, possui atividade catalítica 3 vezes maior na hidrogenação de alcenos, decomposição de peróxido de hidrogênio e oxidação de etanol, quando comparada com platina negra preparada sob agitação mecânica a $1000 \mathrm{rpm}^{29}$, Tabela 2. Adicionalmente, platina negra produzida sob ultra-som apresenta aumento de área de superfície de $62 \%$ e de susceptibilidade magnética de $98 \%$. Estas diferenças foram interpretadas em termos do aumento na quantidade de fase atômica presente, a qual apresentou atividade catalítica maior do que o metal cristalino.

Tabela 2. Efeito de ultra-som em relação à atividade catalítica da platina sob agitação magnética em diferentes reações ${ }^{28}$.

\begin{tabular}{llll}
\hline processo & agitação & \multicolumn{2}{c}{ ultra-som } \\
catalítico & magnética & $2 \mathrm{MHz}$ & $20 \mathrm{KHz}$ \\
\hline decomposição de $\mathrm{H}_{2} \mathrm{O}_{2}$ & 1,0 & 2,60 & 1,35 \\
hidrogenação de 1-hexano & 1,0 & 1,38 & 1,13 \\
oxidação de etanol & 1,0 & 1,40 & 0,74 \\
\hline
\end{tabular}

$\mathrm{Na}$ preparação do cluster nanométrico de ferro depositado em sílica gel sob energia ultra-sônica, obteve-se um catalisador do tipo casca de ovo ${ }^{30}$ porque os clusters de ferro não penetram na sílica.

\section{FONTE DE AGITAÇÃO E DISPERSÃo}

Rao \& Danforth ${ }^{31}$ investigando o efeito da agitação ultrasônica sobre a velocidade de sedimentação, dispersão de sedimento e dispersão da substância filtrada concluíram que o grau de dispersão de sílica após a filtração aumenta com o aumento do nível energético do ultra-som utilizado, diminuindo a área de superfície e o volume dos poros.

Quando dois líquidos imiscíveis, por exemplo água e óleo, são tratados com ultra-som, há aumento na velocidade de formação de gotículas microscópicas com aumento da superfície de contato e das forças coesivas, resultando na formação de microemulsões ${ }^{2}$.

A cominuição de alumina em pó não aglomerada aplicando energia ultra-sônica ${ }^{32}$ durante a moagem úmida causa a redução do tamanho médio de partícula. A forma das partículas de alumina cominuída sob ultra-som é mais esférica do que aquela cominuída pelo método convencional.

\section{OUTRAS APLICAÇÕES}

Uma das aplicações mais utilizadas em ciências dos materiais é a pirólise com pulverizador ultra-sônico ${ }^{33}$ ("ultrasonic spray pyrolysis" - USP) a qual é utilizada para obter partículas finas ou filmes finos. Partículas preparadas por este método têm as seguintes características: forma esférica, distribuição de tamanho uniforme, tamanho de partícula ajustável na razão de mícron a submícron, e alta pureza.

Caracterização não destrutiva ${ }^{34}$ de danos causados pela oxidação de compósitos de matriz cerâmica pode ser realizada por método ultra-sônico.

A utilização do ultra-som em reações no laboratório está se tornando comum e a extensão da tecnologia para reações em escala industrial virá em seguida. Subjacente a estes desenvolvimentos tecnológicos estão os recentes avanços no entendimento da natureza da cavitação e os efeitos químicos do ultra-som.

\section{AGRADECIMENTOS}

M.A.U.M agradece ao CNPq e à CAPES.

\section{REFERENCIAS}

1. Lorimer, J. P.; Mason, T. J.; Chem. Soc. Rev. 1987, 16, 239.

2. Suslick, K. S.; Scientific American 1989, 2, 80.

3. Suslick, K. S.; Yearbook of Science and the Future Encyclopedia Britannia, Inc. 1994, 139.

4. Kupperman, D. S.; Karplus, H. B.; Ceramic Bulletin 1984, 63, 1505.

5. Duarte, L. R.; Arch. Orthop. Trauma Surg. 1983, 101, 153.

6. Xavier, C. A. M.; Duarte, L. R.; Rev. Brasil. Ortop. 1983, 18,73 .

7. Mason, T. J. In Sonochemistry: the uses of ultrasound in chemistry. Mason, T. S., Ed.; The Royal Society of Chemistry; Cambridge, 1990, cap. 1, p. 1.

8. Lorimer, J. P. In Sonochemistry: the uses of ultrasound in chemistry. Mason, T. S., Ed.; The Royal Society of Chemistry; Cambridge, 1990 , cap. 2, p. 9.

9. Kirchhoff, G.; Ann. Phys. Chem. 1868, 134, 177.

10. Suslick, K. S. In Modern Synthetic Methods'; .Schelfold, R., Ed.; Springer Verlag; Berlin, 1986, v. 4, p. 1.

11. Davidson, R. S. In Sonochemistry: the uses of ultrasound in chemistry; Mason, T. S., Ed.; The Royal Society of Chemistry; Cambridge, 1990; cap. 6, p. 69.

12. Boudjouk, P.; J. Chem. Educ. 1986, 63, 427.

13. Barboza, J. C. S.; Serra, A. A.; Quím. Nova 1992, 15, 302.

14. Lorimer, J. P.; In Sonochemistry: the uses of ultrasound in chemistry. Mason, T. S., Ed.; The Royal Society of Chemistry; Cambridge, 1990, cap. 9, p. 113.

15. Henglein, A.; Gutierrez, M.; J. Phys. Chem. 1990, 94, 5169.

16. Donaldson, D. J.; Farrington, M. D.; Kruus, P.; J. Phys. Chem. 1979, 83, 3130.

17. Lindstrom, O.; Lamm, O.; Chemical Effects of Ultrasonic Waves 1951, 1139.

18. Suslick, K. S; Flint, E. B.; Nature 1987, 330, 553.

19. Grebe, J.; Homann, K. H.; Phys. Chem. 1982, 86, 587.

20. Sehgal, C. M.; Wang, S.Y.; J. Am. Chem. Soc. 1981, 103,6606 . 
21. Weissler, A.; J. Am. Chem. Soc. 1959, 81, 1077.

22. Makino, K.; Mossoba, M. M.; Riesz, P.; J. Am. Chem. Soc. 1982, 104, 3537.

23. Makino, K.; Mossoba, M. M.; Riesz, P.; J. Phys. Chem. 1983, 87, 1369

24. De La Rosa-Fox, N.; Esquivias, L.; Craievich, A. F.; J. Non-Cryst. Solids 1990, 121, 211.

25. Davolos, M. R.; Jafelicci Jr., M.; Utrera Martines, M. A.; Ceramics Today-Tomorrow's Ceramics 1991, 969.

26. Bagnall, C. M.; Zarzycki, J.; J. Non-Cryst. Solids 1990 , 121,221

27. Enomoto, N.; Koyano, T.; Nakagawa, Z.; Ultrasonics Sonochemistry 1996, 3, 105.
28. Blanco, E.; Ramírez-Del-Solar, M.; Rosa-Fox, N.; Esquivias, L.; Materials Letters 1995, 22, 265.

29. Lindley, J. In Sonochemistry: the uses of ultrasound in chemistry. Mason, T. S., Ed.; The Royal Society of Chemistry; Cambridge, 1990; cap. 8, p. 102.

30. Suslick, K. S.; MRS Bulletin 1995, 20, 29.

31. Rao, A. S.; Danforth, S. C. Apud Chemical Abstracts 1989, 111, 139278a.

32. Kass, M. D.; Kiggans Jr, J. O.; Meek, T. T.; Materials Letters 1996, 26, 241.

33. Peters, D.; J. Mater. Chem. 1996, 6, 605.

34. Chu, Y. C; Lavrentyev, A. I.; Rokhlin, S. I.; Baaklini, G. Y.; Bhatt., R. T.; J. Am. Cerm. Soc. 1995, 78, 1809. 